\title{
Intimal Hyperplasia
}

National Cancer Institute

\section{Source}

National Cancer Institute. Intimal Hyperplasia. NCI Thesaurus. Code C139160.

Thickening of the tunica intima of a blood vessel due to injury. 